\title{
Laparoscopic Resection and Intracorporeal Anastomosis of a Small Bowel Tumor. Case Report
}

\author{
Alexander Forero-Torres ${ }^{1 *}$, María Reyes Bañeres-Visedo ${ }^{2}$ and María \\ Isabel Prieto-Nieto ${ }^{1}$ \\ ${ }^{1}$ Department of General and Digestive Surgery, Division of Coloproctology, Hospital \\ Universitario La Paz, Spain \\ ${ }^{2}$ Nutritionist-Dietist, Mental Health Nurse, Private Clinic, Madrid, Spain
}

*Corresponding Author: Alexander Forero-Torres, Department of General and Digestive Surgery, Division of Coloproctology, Hospital Universitario La Paz, Spain.
Received: December 16, 2019

Published: January 29, 2020

(C) All rights are reserved by Alexander

Forero-Torres., et al.

DOI: $10.31080 /$ ASGIS.2020.03.0114

\begin{abstract}
Introduction: Small bowel leiomyomas are the most common symptomatic benign small bowel tumor. The treatment of symptomatic lesions are the resection. The laparoscopic approach it is useful in the treatment of malignant and benign small bowel tumors. It will became the first choice approach in the treatment of intestinal tumors. This case report documents the successful removal of a leiomyoma by laparoscopic approach.

Case Report: A 50 year-old man, who was operated of a Retroperitoneal Myelolipoma, was referred to our clinics with a complaint of abdominal pain. Abdominal TC revealed a solid tumor, measuring 3,7 x $3 \mathrm{~cm}$, probably a GIST, adenopathy of $7 \mathrm{~mm}$, and mesenteric panniculitis. We perform a Laparoscopic approach with four to cars and perform a stapler intracorporeal anastomosis using a bag to exteriorized the tumor. The histopathology report showed a intestinal Leiomyoma with margins free of tumor. The patient was discharged 3 days after surgery.

Conclusions: The laparoscopic approach can be used to resect intestinal tumors and perform intracorporeal anastomosis without complications. The patient could benefits of all advantages of a minimally invasive approach.
\end{abstract}

Keywords: Bowel Tumor; Laparoscopic Approach; Intestinal Tumors

\section{Introduction}

Small bowel leiomyomas is the most common symptomatic benign small bowel tumor. Most frequently occur in the jejunum, followed by the ileum and duodenum. These lesions usually remain asymptomatic. Up to $65 \%$ of symptomatic patients typically develop gastrointestinal bleeding or iron deficiency anaemia. Additional symptoms include small bowel obstruction or intussusception and volvulus. Few case reports of symptomatic small bowel leiomyomas have been documented in the literature. The treatment of symptomatic lesions is the resection. The laparoscopic approach it is useful in the treatment of malignant and benign small bowel tumors. It will became the first choice approach in the treatment of intestinal tumors. We recently performed a laparoscopic small bowel resection for an intestinal leiomyoma.

\section{Case Report}

A 50 year-old male, was referred to our clinics with a complaint of six months of abdominal pain with occasional constipation and early satiety, without nauseas or vomiting. The past medical history include a resection of a retroperitoneal myelolipoma two years ago. Upper gastrointestinal endoscopy and Colonoscopy were normal. Abdominal TC revealed a solid tumor, with oval morphology and smooth margins, measuring $3,7 \times 3 \mathrm{~cm}$; the tumor contacts with the ileum and do not have fat plane of separation; The first diagnostic approach is a GIST, also described adenopathy of $7 \mathrm{~mm}$, and findings compatible with mesenteric panniculitis (Figure 1). 


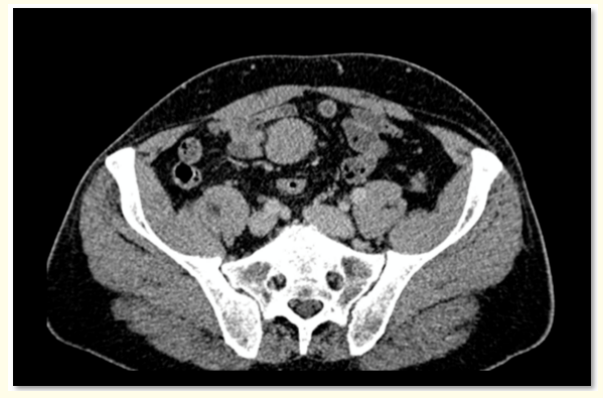

Figure 1: Solid tumor, with oval morphology and smooth margins, measuring $3,7 \times 3 \mathrm{~cm}$; the tumor contacts with the ileum and do not have fat plane of separation.

Under general anaesthesia, we perform a laparoscopic approach with four trocars (a $10 \mathrm{~mm}$ optic trocar using the open technique in the belly button, two $5 \mathrm{~mm}$ trocar placed in the left lower quadrant and epigastric region, and a $12 \mathrm{~mm}$ trocar in the left lower quadrant, all placed under direct vision. General inspection of the peritoneal cavity was normal without adherence. The tumor was located in the ileum at 1,50 $\mathrm{cm}$ from the ileocecal valve. We perform a small bowel resection included the tumor with a lateral-to-lateral intracorporeal anastomosis and closed the enterotomy with simple 3/0 absorbable monofilament stitches (Figure $2,3)$. To exteriorize the small bowel we use a bag and enlarge the incision of the navel trocar. The histopathology report showed a intestinal Leiomyoma with margins free of tumor and mitosis was $<1$ per 10 high power fields. Postoperative recovery was without complications, the oral intake was commenced on the second postoperative day and was discharged from hospital on the third day after surgery.

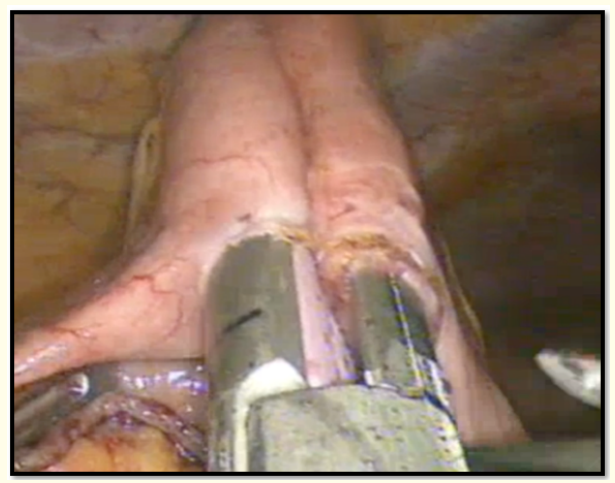

Figure 2: Lateral-to-lateral anastomosis with stapler.

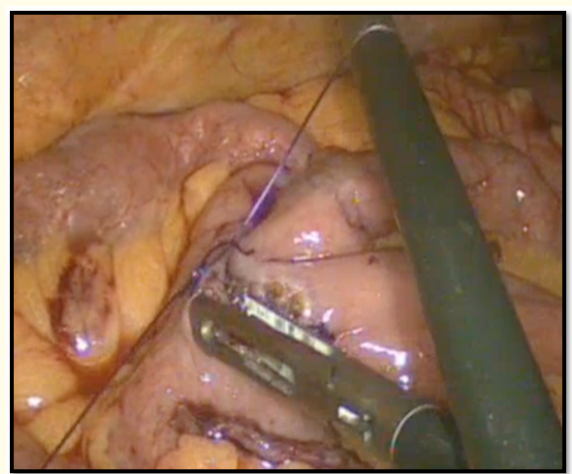

Figure 3: Enterotomy closure with simple 3/0 absorbable monofilament stitches.

\section{Discussion}

The small bowel tumors are uncommon. They comprising only $1-5 \%$ of all GI neoplasms, with only $1-2 \%$ of these being malignant. Although leiomyomas are the most common benign lesions of the small intestine, they are a small proportion of total small bowell neoplasms. Leiomyomas are characteristically well-defined solitary masses and may appear grey or white. Within the small intestine, they can be found intraluminal, extraluminal, or intramural. Not surprisingly, symptomatic leiomyomas can easily be mistaken for other pathologies such as duodenal ulcers and diverticulosis. These tumors are known for bleeding due to central necrosis, liquefaction and expulsion of the tumor's contents into the lumen of the bowel. They are difficult to diagnose because of delayed and nonspecific presentation and after failed conservative treatment for a mistaken pathology Clinicians and Surgeons must have a high index of suspicion [1-6].

\section{Conclusion}

The laparoscopic approach can be used to resect intestinal tumors. It is possible to perform an intracorporeal anastomosis without complications. The technique is safe and reproducible and the patient could benefits of all advantages of a minimally invasive approach with a little scar.

\section{Bibliography}

1. De Latour RA., et al. "Management of small bowel polyps: A literatura review". Best Practice and Research Clinical Gastroenterology 31 (2017): 401-408.

2. Lauren E Smith. "Acute GI bleed due to leiomyoma of the jejunum: a case report". Journal of Surgical Case Reports 7 (2017): $1-3$. 
3. Louis F Chai., et al. "Taking the Lead: A Case Report of a Leiomyoma Causing Duodeno-Duodenal Intussusception and Review of Literature". Case Report in Pancreatic Cancer 2.1 (2016).

4. Hüseyin Cengiz., et al. "A diagnostic dilemma of acute abdomen in pregnancy: Leiomyoma of the small intestine". Journal of the Turkish-German Gynecological Association 15 (2014): 60-62.

5. Perez EA., et al. "Current Incidence and Outcomes of Gastrointestinal Mesenchymal Tumors Including Gastrointestinal Stromal Tumors". Journal of the American College of Surgeons 202 (2006): 623-629.

6. Abbas MA., et al. "Laparoscopic-assisted small bowel resection for a bleeding leiomyoma". Surgical Endoscopy 12 (1998): 995-996.

\section{Assets from publication with us}

- Prompt Acknowledgement after receiving the article

- Thorough Double blinded peer review

- Rapid Publication

- Issue of Publication Certificate

- High visibility of your Published work

Website: www.actascientific.com

Submit Article: www.actascientific.com/submission.php Email us: editor@actascientific.com

Contact us: +919182824667 